\title{
MENTE, CULTURA Y TEORÍA: APROXIMACIONES A LA PSICOLOGÍA DEL ARTE MIND, CULTURE, AND ART THEORY: APPROACHES TO PSYCHOLOGY OF ART
}

\author{
Ángel Pazos-López \\ Universidad Complutense de Madrid \\ angelpazos@ucm.es
}

Cómo referenciar este artículo/How to reference this article:

Pazos-López, A. (2014). Mente, cultura y teoría: aproximaciones a la Psicología del Arte [Mind, Culture, and Art Theory: Approaches to Psychology of Art]. Acción Psicológica, 11(2), 127-140. http://dx.doi. org/10.5944/ap.11.2.14214

\section{Resumen}

El presente artículo es una revisión crítica de las relaciones entre la Historia del Arte y el campo de la Psicología, acotándose el territorio que se ha denominado "Psicología del Arte», dedicado al estudio del arte como producto de la mente humana desde la visión del creador, el receptor y el objeto artístico. El estudio de las ideas que están detrás de las producciones artísticas, o de la sociedad que las descifra y conserva, ha pasado por distintas etapas de desarrollo desde finales del siglo XIX implicando a teóricos del arte, críticos e historiadores, así como a psicoanalistas y psicólogos que han escrito sobre las relaciones entre el arte, la mente y la cultura. Las aportaciones iniciales vinculadas al psicoanálisis de Freud, Jung y Lacan disputaron las primeras posturas filiales y críticas a un campo que se abría. Posteriormente, los escritos de Kris y las teorías de la Psicología del Estilo y de la escuela de la Gestalt serán claves en el devenir de la disciplina. La gran aportación de Vygotsky a la definición de la
Psicología del Arte y sus límites, o los estudios de Gombrich dedicados a la psicología de la representación visual fueron la continuación natural de los planteamientos anteriores, así como los trabajos de Gardner o Vigouroux en las últimas décadas. Este recorrido histórico muestra que la Psicología del Arte es una disciplina que ha estado presente transversalmente en muchas corrientes psicológicas, en permanente actualidad, y que necesita una continuidad al hilo de las últimas corrientes de la Psicología.

Palabras clave: Psicología del Arte; Psicoanálisis; Teoría del arte.

Abstract
This article is a critical review of the intellec-
tual relationsbetween History of Art and a field
of psychology called «Psychology of Art». Psy-
chology of Art studies the art as a product of
human mind from the creator, the receiver and


the artistic object's perspective. The analysis of the ideas behind both artistic productions and society that describes and retains them have undergone various stages of development since the late nineteenth century. This field of study involves art theorists, critics and historians, as well as psychoanalysts and psychologists who have written about the relations among art, mind and culture. The initial contributions of psychoanalysts such as Freud, Jung and Lacan disputed the first critical positions to an opening field. Year later, Kris' writings, and theories of Psychology of Style and the School of Gestalt were crucialfor the future of the discipline. Vygotsky's great contribution to the definition of the Psychology of Art and its boundaries and Gombrich's studies devoted to the psychology of visual representation, were the natural continuation of previous approaches, as well as Gardner'sand Vigouroux's works in the past decades. This historical overview shows how the Psychology of Art has been present in many psychological schools of though at the same time, how it is constantly present nowadays and needs a continuity in line with the latest psychological and theoretical trends

Key words: Psychology of Art; Psychoanalysis; Art Theory.

\section{Introducción}

El término arte proviene del vocablo latino ars, y este, a su vez, del término griego $\tau \dot{\varepsilon} \chi v \eta$, del que deriva la palabra actual «técnica». Las discusiones sobre lo que se considera arte y lo que no, dependen únicamente del observador y de su valoración de las cualidades de los objetos artísticos (Eco, 1968/1970). Así mismo, la percepción de arte que tenía un ciudadano del Egipto faraónico dista mucho de la del hombre de la época victoriana; incluso en nuestros días, la visión sobre el arte que tiene el hombre europeo está bastante alejada de lo que significa para un inuit del ártico. De esta forma, no solamente lo que se entiende por arte, sino también la idea del artista como creador e ideólogo, el valor de los medios expresivos o la finalidad de la obra de arte han ido variando a lo largo de la historia, de forma que no pode- mos hablar de definiciones claras y precisas para todos estos conceptos (Billgren, 2011). Lo que dota a las manifestaciones expresivas la cualidad de ser obras de arte viene determinado, no tanto por su condición material, como por algunos principios que tienen que ver con quién, cómo, dónde y cuándo se realiza la obra. Elementos como la voluntad de crear arte por parte del artista (intencionalidad de expresar sentimientos o ideas), la pervivencia histórica que asegura el interés de una creación por su vinculación con sociedades o realidades del pasado, o el poder del experto cuando tasa y valora económicamente una creación actual. Sin embargo, los límites del término arte son completamente subjetivos: lo que para un colectivo puede ser artístico, puede generar rechazo para otro (Mirzoeff, 1999/2003).

Si tenemos en cuenta el enorme panorama que nos presenta cualquier Historia del Arte podemos plantearnos la premisa de si realmente hay algo que tengan en común todos los fenómenos artísticos. La respuesta es compleja, pero nos lleva a reflexionar sobre la función del arte en las sociedades, planteándonos cuestiones como la consciencia de estar creando arte, la necesidad humana de expresar sentimientos y pensamientos, o simplemente sobre la intención de hacer reflexionar al espectador sobre lo que está observando (Schuster y Beisl, 1978/1982). Tal vez sea más fácil ver la intención expresiva y creativa en un cuadro de Kandinksky que en un templo griego, dedicado al dios Poseidón. En el primer caso, es el autor quien conscientemente pinta algo con la voluntad de que su obra genere reflexión en el espectador, a partir de las líneas, formas y colores. En el segundo caso, la intención de los arquitectos griegos era la de dar respuesta a la necesidad social de la práctica del culto, mediante un edificio acorde a la idea de belleza y el gusto, no personal, sino de la época. La cuestión de si ese gusto estético se rige por unos cánones universales en la mente humana y de cómo se perciben las obras de arte por sus espectadores, en su tiempo y en el nuestro, son el objeto de la Psicología del Arte (Schuster y Beisl, 1978/1982).

Las diferentes formas de analizar el arte aportan perspectivas tan diversas como los so- 
portes de las mismas obras. Así, la Psicología del Arte es el campo de estudio interdisciplinar que se encarga de analizar la creación artística y su apreciación, en relación con la mente humana. La disciplina está relacionada dentro de la Psicología con otros campos de estudio como la Psicología Básica (la percepción, el pensamiento, la memoria, el lenguaje o la emoción), Social, Evolutiva, Diferencial, de la Personalidad, la Psicopatología o la Psicobiología (Weber, 1958/1966). A su vez la Psicología del Arte es uno de los métodos historiográficos de análisis del fenómeno artístico, dentro de los estudios teóricos de la Historia del Arte. El campo de la Psicología del Arte es tan rico que hasta el momento se ha centrado en cuestiones como la intencionalidad del autor al crear una obra de arte, la plasmación del «yo» en la obra y su análisis, la percepción artística y su significación, las aportaciones del receptor a la dimensión artística, el gusto estético y su validez, etc. (Álvarez, 1974; Hogg, 1969/1975). Para ello, la disciplina ha centrado su análisis en tres focos de atención, que han sido interpretados por la mayoría de las corrientes: la perspectiva del creador, centrándose en la capacidad del artista como genio o en la problemática psíquica de la producción artística; la perspectiva de la obra o del producto del arte; y la perspectiva del espectador, como receptor de la experiencia estética y su aportación a la interpretación del arte (Marty, 1997).

Para hacer un recorrido histórico breve sobre las líneas claves de la Psicología del Arte nos acercaremos a los primeros planteamientos psicoanalíticos para concebir y analizar el fenómeno artístico de la mano de autores como Freud, Jung y Lacan, así como sus críticos y seguidores. Con posterioridad nos introduciremos en las interpretaciones de la Psicología del Arte a partir del concepto de Estilo (Worringer) y de la Psicología de la forma (en especial la escuela de la Gestalt y Arnheim), sin olvidarnos de las aportaciones de Kris, que actúa como puente entre estas corrientes y el psicoanálisis. Seguirán las aportaciones de Vygotsky a la Psicología del Arte y las líneas fundamentales del pensamiento de Gombrich en el marco de la historia cultural y la Psicología de la representación. Para concluir, vere- mos las últimas tendencias en la disciplina y sus planteamientos de futuro.

\section{Arte y Psicoanálisis}

El psicoanálisis nace a finales del siglo XIX como una práctica terapéutica orientada al tratamiento de las fobias, neurosis y otras enfermedades psíquicas. La evolución de la praxis lleva a la disciplina a interesarse por otro tipo de problemas que no están directamente relacionados con el ámbito clínico, como la religión, los mitos o el arte.

\section{Sigmund Freud y su aplicación del psicoanálisis al arte}

Sigmund Freud (1856-1939) es el fundador de la corriente psicoanalítica y sus planteamientos sobre las relaciones entre esta disciplina y el arte han recibido mucha contestación. Freud fundamenta el psicoanálisis en el método de la asociación libre por el cual el sujeto de análisis manifiesta sin ninguna restricción, orden o control las ideas y los pensamientos que se le presentan. Al aplicar este método a las obras de arte, se plantea la posibilidad de trazar perfiles analíticos a los autores a partir de los rasgos psicológicos que se muestran en la manera de ejecutar las obras. Esto es posible porque para Freud el arte es «un camino por el que el sueño se vuelve realidad» y las obras de arte encierran significados simbólicos que el artista plasma a través de la catarsis y que le permite sublimar un impulso sexual reprimido en el inconsciente. Para Freud, es posible analizar rasgos psíquicos de los artistas al descifrar los símbolos ocultos en sus obras, que plasman de forma inconsciente, considerando a su vez que el proceso creativo estaba íntimamente ligado a los instintos (Gombrich, 1971).

En la obra Un recuerdo infantil de Leonardo da Vinci (1910/2001), Freud lleva a cabo un examen psicoanalítico de este artista, basándose en un texto del mismo en el Codex Atlanticus donde narra un sueño que Leonardo da Vinci tuvo de pequeño. En dicho sueño, un 
animal (que la traducción que manejaba Freud identificaba con el buitre) «le abrió la boca con su cola y le golpeó con ella repetidamente entre los labios». A partir de este pasaje, Freud desarrolla una interpretación del cuadro $\mathrm{La}$ Virgen con el Niño y Santa Ana (Musée du Louvre) vinculada a la homosexualidad del artista y a la manifestación de un posible complejo de Edipo. Para ello, pone en relación el sueño de la niñez y la presencia de supuestas fantasías sexuales con la representación andrógina del buitre en la cultura egipcia y con la figura del buitre que aparecería subyacente en el cuadro. Por otra parte, se vincula la presencia de la Virgen y de Santa Ana con la dualidad de cariño existente en la infancia del artista, que fue criado por dos madres (la madre biológica, campesina, y la madrastra, noble).

Más tarde, Freud publica El Moisés de Miguel Ángel (1914/2011), texto en el que plantea una interpretación de la obra italiana diferente a la más extendida en ese momento, según la cual Moisés está representado en el acto de girar la cabeza y entrar en cólera al ver a su pueblo adorando al becerro de oro. Para Freud, en cambio, la escultura representa una acción inhibida entendida como un momento de contención, que se puede apreciar a partir del gesto de Moisés de agarrarse la barba, sujetando así su pasión. Esto se asocia con la intención de Miguel Ángel de representar el conflicto interno de la lucha por sujetar la furia.

Los planteamientos de Sigmund Freud han sido múltiplemente cuestionados, no solamente en el campo de la aplicación del psicoanálisis en el arte. Por una parte, los fundamentos sobre los que se asientan sus teorías han sido considerados meramente interpretativos y el método de la asociación libre no es reconocido por todos como un método científico. También se ha considerado que los preceptos freudianos parten de la simplificación y reducción para pretender una universalidad ficticia en la práctica clínica. Finalmente, sus planteamientos que minusvaloran lo femenino y consideran la homosexualidad como una patología también ha recibido gran contestación (Schneider, 1996).
Por otra, dentro de sus estudios relacionados con el arte, la psicobiografía de Leonardo da Vinci fue muy rebatida al descubrirse un error en la traducción del Codex Atlanticus que se manejaba hasta el momento. El pájaro del sueño del artista había sido traducido erróneamente por buitre, cuando en realidad se trataba de un milano, con la consiguiente imposibilidad de aplicar correctamente las interpretaciones freudianas. Este error sirvió para generar reservas sobre la utilización del psicoanálisis como método historiográfico, pese a que hay que reconocer que la equivocación solamente afecta a estos resultados en concreto y no al método. Aun con esto, autores posteriores cuestionaron la vigencia del método por plantear supuestos que al ser aplicados al pasado resultan anacrónicos y no concuerdan con la forma de pensar de la época. Otro factor clave reside en la complejidad para encontrar fuentes documentales que puedan ser contrastadas para realizar aseveraciones clínicas sobre los pensamientos de personajes del pasado (Hatt y Klonk, 2006).

\section{Carl Gustav Jung y el inconsciente colectivo}

Carl G. Jung (1875-1961) fundó la escuela de psicología analítica. A pesar de ser un seguidor de Freud en una etapa inicial, acabó por distanciarse de sus planteamientos. Mientras que Freud mantenía una visión pesimista del ser humano, donde una vida equilibrada se regía por la continua represión de pulsiones negativas del inconsciente vinculadas a la sexualidad, para Jung el inconsciente es una fuente inagotable de creatividad que podía ser terapéutica. Si Freud basaba su enfoque en la patología, Jung se centra en el ser humano, derivando de esto un equilibrio entre el diagnóstico terapéutico de la enfermedad y la detección de lo que funcionaba correctamente.

En el campo artístico-cultural, Jung creía en la existencia de los arquetipos (formas simbólicas) comunes a todos los seres humanos, que anulan las diferencias culturales y la especificidad histórica. En El hombre y sus símbolos, el autor expone su idea de inconsciente co- 
lectivo a partir del análisis de símbolos que laten en todos los seres humanos de manera independiente a la civilización, época y cultura a la que pertenezcan (culto al sol, el agua, el fuego, la madre, la esposa, etc.). Al hablar del simbolismo de las artes visuales, sus ideas se relacionan con las del historiador del arte alemán Aby Warburg, que proponía analogías transculturales como fenómenos del inconsciente. En el pensamiento del autor, los arquetipos se plasman mediante la creación artística, con un profundo carácter terapéutico (Jung, 1964). De esta forma, el proceso espontáneo de pintar o modelar supone un medio de expresión que puede ayudar a los pacientes a manifestar un «inconsciente desbordante» que posibilita el contacto con las emociones más profundas de la persona (D'Alleva, 2005).

Para Jung, la visión del artista también se distancia de la de Freud, considerando que el proceso vital de los artistas está marcado por un lado por la búsqueda de la felicidad, de la seguridad y de la vida, y por el otro la pasión creativa que se impone al deseo personal y anula la libertad individual. Este contraste vuelve al creador un instrumento del arte y supera fines personales que pueda tener el artista, convirtiendo el proceso creativo en un medio de expresión del inconsciente colectivo. La obra de Jung fue un referente para artistas contemporáneos que, a partir de sus ideales sobre la creación artística y la plasmación del inconsciente, se vieron influidos por sus escritos como Jackson Pollock, Federico Fellini, Luis Buñuel, Peter Birkhäuser, Remedios Varo o Leonora Carrington.

\section{EI espejo y la mirada de Jacques Lacan}

Las aportaciones de Jacques Lacan (19011981) al psicoanálisis son fundamentales para entender el desarrollo de la disciplina, ya que integra en ella elementos de la semiótica, la lingüística y el estructuralismo. Lacan no dejó ningún escrito propio, y sus aportaciones nos llegan por edición de los seminarios que impartía, con una profunda erudición y solidez.
El autor aplica al psicoanálisis fundamentos de la lingüística estructural cuando desarrolla conceptos como la cadena significante o el inconsciente estructurado como lenguaje. Según esta última teoría se deben distinguir tres registros del inconsciente: lo real, aquello imposible de conceptualizar, que se plasma a través de lo imaginario y lo simbólico; lo imaginario, dimensión en la que tiene lugar el pensamiento en imágenes en sentido semiótico (imagen visual, palabra y sonido); y lo simbólico, aspecto esencialmente lingüístico en el que se expresan significantes y significados.

Es fundamental, además, la aportación del estadio del espejo, la etapa de desarrollo infantil que para el autor está comprendida dentro de «lo imaginario» y que tiene lugar entre los seis y dieciocho meses de edad. En ella el infante es capaz de percibirse y reconocer su imagen en un espejo. En vez de observar únicamente las partes de su cuerpo que puede observar de forma directa, el niño muestra alegría por verse a sí mismo por completo, comenzando a formarse desde ese momento la visión de un "yo» como un todo. En oposición a los sueños de conformación de ese "yo», Lacan menciona la aparición de sueños donde se reflejan miembros mutilados y aparece el cuerpo despedazado, como reacción al miedo de desintegración del individuo, utilizando como ejemplo las creaciones de El Bosco como El jardin de las Delicias del Museo del Prado (Harrison y Wood, 2003).

En cuanto a la concepción sobre el arte, Lacan pensaba que las obras artísticas inventaban maneras nuevas de trabajar con la ilusión para proyectar realidades que imitan a los objetos que representan, pero cuyo fin no es la propia representación, sino su apariencia. Al igual que Freud, Lacan entiende el arte como sublimación. Sin embargo, para este último, la psicobiografía del artista a partir de su obra de arte es inútil y carece de fundamento. De esta forma, la dirección lacaniana implicaría utilizar las obras de los artistas como «textos» y no tratar de analizarlas psicológicamente. Cuando Lacan utiliza y menciona las obras de arte no es para analizarlas sino para ejemplificar conceptos de la teoría psicoanalítica. Por ello, no podemos hablar realmente de psicoanálisis del 
arte en Lacan, sino de las relaciones de las ideas del autor con la creación y recepción de las obras de arte (D'Alleva, 2005).

También es fundamental para el estudio de la percepción artística la distinción que el autor realiza entre ver y mirar (eye and gaze). Cuando nos referimos a ver, hablamos de una función del «yo». Por su parte la mirada es un acto del «otro». Para ilustrar sus tesis sobre el ojo y la mirada, Lacan utiliza recurrentemente el cuadro de Holbein, Los embajadores. En el mismo, se observa sin dificultad a los dos personajes representados, Jean de Dinteville y Georges de Selve, apoyados en un mueble que aglutina diversos objetos con significados simbólicos. Sin embargo, lo que más llama la atención al contemplar la obra es que en su primer plano hay un objeto plasmado de forma difusa en la parte inferior central del cuadro. Se trata de una calavera representada en anamorfosis, es decir, distorsionada para que pueda verse únicamente desde un único punto de vista. Para Lacan, este efecto en el cuadro nos ejemplifica perfectamente sus teorías sobre la mirada y sus formas. La parte del cuadro que observamos solamente de costado muestra el deseo de mirar, puesto que el objeto causa de deseo, visto de frente no es nada, solamente adquiere forma al mirarlo al sesgo. Estos planteamientos de Lacan se relacionan con los estudios que desarrolló Ernst Kris sobre de la importancia de la recepción y percepción de la obra de arte por parte del espectador (Harrison y Wood, 2003).

\section{Otras aplicaciones del psicoanálisis al arte}

Además de los autores mencionados, el psicoanálisis ha evolucionado desarrollando otras propuestas de integración de las manifestaciones artísticas con sus teorías, no solamente centradas en el análisis de la personalidad de los autores de las obras de arte, sino en los mecanismos psíquicos implicados en la creación artística y su expresión, a la vez que en la recepción y percepción del arte.
El filósofo Richard Arthur Wollheim (19232003) retoma la idea de la pintura como expresión de deseos inconscientes no expresables a través del lenguaje. Sin embargo, rechaza el concepto del impulso o instinto artístico como originalidad, ya que el hombre no puede desprenderse de su faceta social que le hace formar parte de unos moldes sociales (Wollheim, 1984). Su visión se contrapone a la que defiende Rosalind Krauss, aplicando los esquemas de Lacan. Para ella, la creación artística se escapa del control del autor, siendo expresada a través de un deseo del inconsciente (Krauss, 1993).

Desde el feminismo, otras visiones han matizado los fundamentos del psicoanálisis, como Laura Mulvey que aplica el concepto lacaniano de mirada al problema de la masculinización de la percepción artística (Mulvey, 1975), o Griselda Pollock utilizando los conceptos del psicoanálisis para analizar la pintura de los prerrafaelitas y su relación con la concepción de la mujer (Pollock, 1988). También es importante la lectura del psicoanálisis por parte de historiadores y críticos de arte como Mieke Bal, que aplica la teoría del espejo de Lacan en sus estudios sobre Rembrandt y Caravaggio (Bal, 1991), o Hal Foster que pone en práctica los modelos psicoanalistas (Foster, 1996).

\section{Arte, Estilo y Forma}

\section{Los antecedentes: la Einfühlung y la psicología del estilo}

La psicología del estilo fue la corriente que analizó el devenir de los fenómenos artísticos relacionando los valores formales con su expresión sentimental, para interpretar las motivaciones históricas que subyacen en la obra de arte. A pesar de que no es una escuela psicológica como tal, entender su fundamento sirve para evidenciar una propuesta más de las relaciones entre la mente y el arte, y es fundamental para el desarrollo de corrientes posteriores. Tiene su antecedente en la corriente de la estética experimental y en la teoría de la proyección sentimental (Einfühlung), que es una línea de pensamiento que relaciona la 
experiencia de los sentimientos y emociones con la expresión y percepción artística.

\section{La teoría de la proyección sentimental}

A partir de los escritos del filósofo y psicólogo Gustav Theodor Fechner (1801-1887), de su obra Elementos de psicofísica (1860) y en especial su Estética Experimental (1871), se empieza a considerar la existencia de una conexión entre la obra de arte y las vivencias personales que se evocan en el espectador, ejerciendo una gran influencia en los estudios posteriores sobre la percepción. Por otra parte, Friedrich T. Vischer (1807-1887) en Estética o ciencia de lo bello (1857), trabaja la idea positivista de que el arte se produce en el cruce entre una idea y su manifestación, con una clara vinculación sentimental. De esta forma, para lograr el conocimiento de las cosas es necesario que proyectemos sobre ellas nuestra experiencia personal y subjetiva, ya que la percepción actúa como un proceso de identificación simbólica con las vivencias emotivas personales.

Más tarde, su hijo Robert Vischer (18471933) es quien acuña el término Einfühlung aplicándolo al campo de la percepción, incluyéndolo en su tesis doctoral Sobre el sentimiento óptico de la forma publicada en 1873, La proyección sentimental o endopatía (Einfühlung) es un fenómeno psíquico por el que artistas y espectadores incorporan al proceso creativo y perceptivo sus sentimientos, emociones y experiencias personales que condicionan su reacción ante los estímulos artísticos.

La aportación de Theodor Lipps (18511914), con su obra Los fundamentos de la Estéti$c a$ en 1906, matiza la proyección sentimental al aplicarla a la concepción del arte como una realidad puramente humana. A través de la expresión artística el hombre se reencuentra consigo mismo en un proceso de autoconocimiento, que Lipps pone en relación con la idea del subconsciente. En cuanto a la percepción, el autor propone una estética del espacio en la que los elementos como la luz o el color son interpretados con rasgos paralelos del alma del espectador, que los percibe e interioriza de forma inconsciente dotándolos de un significado personal.

Para todos estos autores el sentimiento actúa como una forma espiritual, sin reglas lógicas que la estructuren, que transforma la experiencia de percepción en un acto estético. El centro de la reflexión sobre la obra de arte debe plantearse en torno a la vida espiritual del artista expresado en la misma, más que los temas desarrollados. También se evidencia el valor de la participación del espectador como predisposición sentimental hacia la obra de arte (e.g., Harrison, Wood y Gaiger, 1998; Domínguez, 1993; Francés, 1979).

\section{Wilhelm Worringer y la Psicología del Estilo}

Retomando el concepto de Einfühlung, el historiador del arte Wilhelm Worringer (18811965) compuso la obra Abstracción y Naturaleza: una contribución a la Psicología del Estilo. La clave del recorrido histórico del arte se centra, para Worringer, en momentos de naturalismo clasicista (donde el arte se entiende como la representación canónica de la realidad) y etapas abstractas en las que el arte se libera de la contingencia del naturalismo. Estas dos tendencias tienen su origen en las manifestaciones artísticas de la Prehistoria y se desarrollan a lo largo de todo el arte posterior: las culturas con una mayor actividad espiritual tienden a la abstracción en sus obras, mientras que las sociedades en las que predomina la actividad científica, evidencian formas artísticas más naturalistas (Worringer, 1908/2008). Con este despliegue conceptual, el autor se aparta de la concepción académica que entiende el arte unívocamente como representación de la realidad. A pesar de que para Worringer prepondera el gusto por la abstracción, como plasmación artística más elevada en la que el ser humano puede reposar del caos universal, reconoce el valor de lo orgánico y naturalista, como fundamento de la estética.

De esta manera, para el autor, el devenir de las manifestaciones artísticas a lo largo de la historia está marcado por los cambios en la vo- 
luntad artística. El estilo se entiende a partir de la confluencia de la voluntad artística (formville), la proyección sentimental y la visión del mundo del momento. Los valores de la forma se comprenden como expresión del significado de la obra de arte, desapareciendo la dualidad entre forma y contenido. El autor también establece la diferenciación entre la estética, como disciplina dedicada al estudio de la belleza y la reproducción de los modelos clásicos, y la ciencia o teoría del arte, cuya función es explicar todas las manifestaciones artísticas. Para el autor, la confusión entre ambos campos había originado una concepción del arte como capacidad para la reproducción de modelos naturales, sin atenerse a la diversidad y pluralidad estilística (Worringer, 1908/2008).

A partir de la obra El arte y sus interrogantes, introduce el concepto de sentimiento vital en el proceso de creación artística, relacionándolo con la cosmovisión (posición desde la que el hombre contempla el mundo) y el desarrollo psíquico. Las visiones del mundo orientales o primitivas suponen una voluntad de forma abstracta porque son sociedades regidas por el misticismo. Sin embargo, el hombre griego antiguo o el renacentista de la Italia del siglo XVI, tienen producciones más relacionadas con el naturalismo, por la pretensión de acercamiento a la realidad mediante la importancia de la ciencia en los ambientes sociales (Worringer, 1956). Esta dualidad de conceptos enfrentados es la clave del pensamiento del autor.

\section{Del psicoanálisis a la psicología de la percepción: Ernst Kris}

El historiador del arte y psicoanalista Ernst Kris (1900-1957) es uno de los puentes entre los estudios del psicoanálisis aplicado al arte y de la psicología de la percepción. Formó parte del grupo de seguidores de Freud como psicoanalista, labor que compaginó con su cargo de conservador del Museo de Viena. A partir de su aproximación a ambas disciplinas, analizó la obra del escultor del siglo XVIII Franz Xaver Messerschmidt, que había esculpido una colección de bustos personificando distintos tipos de caracteres humanos, detectando su trastor- no mental. Posteriormente, y trabajando con Ernst Gombrich, estudió el desarrollo de la caricatura, vinculando la aparición del género a la desaparición de la creencia en la magia, como entorno posibilitador de la exageración expresiva en la imagen. En su obra Psycoanalytic Explorations in Art, Kris nos habla de su concepción del arte como un proceso de satisfacción de la mente. A partir de la recuperación de la obra de Freud y sin distanciarse de sus interpretaciones, profundiza en cuestiones como la recepción de la obra de arte por parte del espectador. Para el autor, la contemplación activa de una obra de arte por parte del público completa el significado que el artista le otorgó en su creación. De esta manera, los artistas utilizan la actividad consciente para dar forma a su material inconsciente. El espectador, por su parte, realiza el proceso inverso: percibe la obra de arte conscientemente y posteriormente la interioriza de manera inconsciente, posibilitando un nivel superior de comunicación con sus contenidos (Kris, 1952). Para Kris -al igual que para Lacan-, no existe una psicología psicoanalítica del arte, ya que no hay elementos y fuentes suficientes para investigar las raíces de los dones o el talento creativo. Así, los procesos mentales relacionados con el arte -creación y percepción- son un problema del que no se puede esperar solución desde esta disciplina.

\section{La psicología de la forma (escuela de la Gestalt)}

En 1890 Christian von Ehrenfels publica el texto Acerca de las cualidades de la forma, reconocido como el fundamento de la Escuela de la Gestalt, una corriente psicológica cuyos máximos exponentes han sido figuras como Wolfgang Köhler, Max Wertheimer, Kurt Koffka o Kurt Lewin. La palabra alemana Gestalt significa forma, figura o configuración. Se desarrolla pues una línea de pensamiento vinculada al estudio del proceso de la percepción humana, al pensamiento y a los procesos de resolución de problemas. Así, nuestra mente percibe elementos del medio y los relaciona con la totalidad, dentro de un sistema superior. 
El proceso de percepción no implica la suma de las unidades elementales, sino la captación del todo (Vestegen, 2005).

La psicología de la Gestalt considera que la percepción es un proceso mental activo mediante el que se contemplan las formas externas hasta determinar cual es el esquema estructural que adopta (por ejemplo, ante el estímulo de una pantalla de televisión, el concepto de rectángulo). Sobre la creación artísti$\mathrm{ca}$, se resalta el valor de la estructura formal por encima de los significados sentimentales que puede despertar la obra de arte en el espectador. A pesar de esto, la representación artística (en cuanto a la imitación de un modelo o a la plasmación de realidades) no es entendida como un acto de reproducción, sino como una creación nueva que equivale a lo representado, en tanto que se ajusta a su forma. Para la escuela de la Gestalt el arte es la elaboración de la realidad y de la propia experiencia del público a partir de la configuración mediante formas. La psicología de la Gestalt influyó potentemente en la evolución de la Psicología del Arte, no solamente por proponer teorías que condicionaron la manera de entender la percepción estética, sino por el eco que tuvieron estas en personalidades posteriores (Arnheim, 1966/1995; 1986/1989).

Uno de los autores formados en el círculo de la Gestalt que más relevancia ha tenido en la psicología del arte es Rudolf Arnheim (19042007). Desde el punto de vista teórico, se aleja de la psicología del estilo y se adhiere a los planteamientos de la psicología de la forma, al plantear que toda representación visual tiende a la abstracción como medio de simplificación estética -pese a que el resultado de la obra no sea abstracto-. En su libro Arte y percepción visual. Psicología del ojo creador se encarga de definir las categorías visuales mediante las cuales el arte elabora configuraciones y la percepción es capaz de asimilar sus estructuras. Para ello dedica un capítulo a cada uno de los diez conceptos visuales fundamentales: equilibrio, figura, forma, desarrollo, espacio, luz, color, movimiento, dinámica y expresión. Para Arnheim, el proceso de percepción consiste en que el espectador desvela en las imágenes los conceptos anteriormente señalados.
Esos conceptos son, en esencia, más relevantes que la carga simbólica, sentimental o temática que pueda subyacer en la obra de arte (Arnheim, 1954/2005).

Por su parte, en su obra El pensamiento visual, plantea la problemática de los límites del lenguaje. Para el autor, existen cualidades en las obras de arte imposibles de ser expresadas en palabras, porque el lenguaje no posibilita un medio directo de captación de la realidad -solamente es útil para denominar aquello que ha sido captado mediante los sentidos y procesado por la mente- (Arnheim, 1969/1986).

A pesar de las grandes aportaciones conceptuales que la psicología de la forma incorpora a el estudio psicológico de la realidad artística, sus teorías no tienen la suficiente amplitud para resolver los problemas históricos del arte. De esta manera, las dinámicas de cambio que se desarrollan en el devenir de estilos y tendencias artísticas, quedan subordinadas al aspecto simplista de su reducción formal, sin que exista una justificación teórica que aporte luz sobre la trayectoria de evolución del arte. Por su parte, a Arnheim se le ha rebatido que para explicar sus planteamientos teóricos no se fundamente en la estricta fenomenología de la percepción visual, recurriendo a las realidades contextuales que no se explican directamente con su pensamiento visual (Monserrat, 1998).

\section{Arte, desarrollo social y cultura}

\section{El arte como fenómeno sociocultural: la psicología del arte de Vygotsky}

Lev Semionovich Vygotsky (1896-1934) es uno de los autores más importantes para la psicología del arte. En su obra se aprecia una clara influencia de las ideas socialistas soviéticas que comenzaban a extenderse de forma coetánea al desarrollo del pensamiento del autor. Estos rasgos relacionados con enfoques sociológicos se resumen en el alejamiento de Vygotsky del análisis de obras de arte como elementos independientes que implicarían visiones subjetivas, como sí realizaba Freud, por 
ejemplo. Para Vygotsky, la importancia de trazar una psicología del arte reside en el análisis global del fenómeno artístico, rechazando las interpretaciones parciales y sesgadas que analizan la psicología de un autor a partir de sus obras (Kozulin, 1990).

Su tesis doctoral, Psicología del arte, escrita en la década de los 30 y publicada a finales de los sesenta, traza los principales problemas de la materia con una visión rigurosa y sintética, abordando lo que se había escrito sobre el tema hasta el momento. En la primera parte, el autor trata de justificar la existencia de una psicología del arte como disciplina dentro de la psicología, acotando sus fundamentos y los principales problemas para definir su existencia (Vygotsky, 1968/2006). Posteriormente, define la idea de una naturaleza social e histórica de la conciencia humana que se plasma a través de la creación artística. En la segunda parte de la obra, el autor centra su discurso en el análisis del material artístico literario (fábula, narración y teatro) como ejemplificación del resto de dimensiones artísticas. Evoca, en este momento, su texto $\mathrm{La}$ tragedia de Hamlet, príncipe de Dinamarca, de William Shakespeare de 1916, que escribió con tan solo 19 años. En la parte tercera, el autor expone su teoría de la catarsis como fundamento de la expresión artística. La obra hace especial énfasis en las emociones, la imaginación y la fantasía, que serán conceptos que acompañarán la explicación de su discurso. De esta manera, la psicología del arte, para Vygotsky, debe ser la disciplina encargada de desvelar las claves psíquicas implicadas en la creación y recepción de los procesos artísticos. La importancia de la dimensión social del fenómeno artístico y la visión de la psicología social, la precisión de la parte emocional de los fenómenos estéticos, la lectura de la faceta artística en relación con las fases de desarrollo de la persona y la psicología evolutiva o la relación e integración de los procesos artísticos con la formación y educación, son algunos de los problemas de los que nos habla la Psicología del Arte planteada por el autor (Vygotsky, 1968/2006).

Para Vygotsky, el arte lo conforman tanto la habilidad técnica de crear, como la capacidad de expresar una visión particular del mundo en relación con el contexto social del artista. Toda creación artística, por original que parezca, fruto del genio creador del autor, siempre es consecuencia del diálogo de este con su entorno cultural, personal y social. En consecuencia, el proceso artístico está vinculado a lo que el autor denomina pensamiento emocional, porque el deseo fundamental para los artistas al crear una obra es generar emociones o sensaciones en los espectadores. Se convierte así en una experiencia estética, comunicativa y puramente social, porque su fin último es comunicar y hacer sentir valores y emociones personales a otros individuos. Desde el punto de vista social, el arte hace confluir la estética y la ética al suponer un medio para reflejar valores e ideas. El autor introduce en este momento el concepto de catarsis para referirse al momento exacto de descarga energética por la que se realiza la creación artística, que es entendida como el choque entre la forma y el contenido. La educación artística tiene, para el autor, una enorme importancia porque ayuda al desarrollo mental y a la evolución de la persona. Esta será una idea que el autor retoma en el ensayo La imaginación y el arte en la infancia (Vygotsky, 1930/2003), donde trazará los límites entre imaginación y realidad poniéndolos en relación a los mecanismos creativos de la infancia y la adolescencia.

Los planteamientos de Vygotsky fueron cuestionados desde el ámbito de la psicología cognitiva por otorgar un papel preponderante al carácter emocional del ser humano y a lo sentimental, elementos poco objetivos para el análisis de la conducta del hombre. Además, la vinculación del autor con las ideas de la Rusia soviética hacen centrar sus reflexiones en el carácter social de la persona, alejándose de las consideraciones individualistas (Kozulin, 1990). Pese a esto, sus planteamientos han tenido una cierta continuidad en los últimos años. Por su parte, la vinculación de la educación con la faceta artística ha sido trabajada también por Howard Gardner (1982/1997; 1994/1997), estudiando los distintos procesos de la expresión artística, con especial atención a la formación en los primeros años de vida y a la potenciación de las facetas artísticas como 
medio de comunicación. Así mismo, un interesante análisis del artista es el realizado por Roger Vigouroux (1992/1995), donde vincula la faceta del genio creador con los fundamentos neuropsicológicos de la experiencia estética, analizando las conexiones con la mentalidad infantil para la creación artística, en la línea de los dos autores que hemos mencionado con anterioridad.

\section{El arte y la historia de la cultura: la psicología de la representación de Ernst Gombrich}

Ernst Gombrich (1909-2001) ha sido uno de los historiadores de la cultura que más ha desarrollado la idea de imbricación entre pensamiento y arte, incorporando lo que él mismo denominó psicología de la representación visual (Gombrich, 1960/1987). Su vinculación al foco cultural de la Viena de los años 20, al igual que su etapa en el Instituto Warburg, fueron significativas para entender sus planteamientos intelectuales que se revelan a través de su enorme producción escrita.

En su concepción del arte, incorpora de la semiótica la idea de que las obras tienen a la vez significante y significado -forma y contenido-, que deben ser estudiados en igual medida, frente a las teorías previas que se centraban en uno u otro aspecto. A su vez, las interpretaciones artísticas deben estar en consonancia con el momento de la historia en el que se desarrolla la obra, pero sin producir el desenfoque de concebir el pensamiento como único en un mismo momento histórico y lugar. A pesar de no desarrollar una teoría en la que se analice la esencia del arte, el autor considera que el impulso artístico está presente en todos los períodos de la historia de la humanidad, sin embargo, no existe una definición de arte, existen obras artísticas que se definen por si mismas. La obra de arte, para Gombrich, es el resultado de la combinación de los elementos comunicativos expresados por el artista, con la percepción del espectador que se conforma a partir de sus experiencias personales y culturales (Gombrich, 1960/1987).
Su obra más representativa, Arte e ilusión. Estudio sobre la psicología de la representación pictórica, nos muestra un panorama de la trayectoria de la imagen vinculado tanto a las técnicas artísticas y pictóricas como al desarrollo de los hábitos perceptivos del espectador. El autor critica el convencionalismo del naturalismo artístico y lo vincula a la evolución personal del artista, que sigue el método de «ensayo/error» al experimentar con muchas fórmulas creativas para lograr unos resultados que no son predecibles. Gombrich cuestiona la eficacia de los análisis psicoanalistas e iconográficos que se centran en las intenciones del artista al crear la obra y se pierden en aspectos secundarios. Propone una psicología de la representación donde se tenga en cuenta la historia de la cultura como elemento dinámico que posibilita la interpretación de los fenómenos artísticos (Gombrich, 1956/2008). A pesar de que los mecanismos perceptivos del ser humano son los mismos, la representación deriva en modelos muy diferentes, porque no se fundamenta en la percepción sino en las ideas o conceptos del artista sobre las cosas. El artista no puede pintar lo que ve, porque el proceso de comparar es posterior a la ejecución de la obra. Solo en el momento en el que la acaba, o cuando tiene los trazos ya ejecutados, puede comprobar si lo que ha creado se parece al modelo. Para ello, no puede aislarse de sus ideas y su imbricación social y cultural: no existe, por tanto el «ojo inocente», ajeno a la subjetividad de representación. Lo que hace el artista es, por el contrario, crear ilusión de realidad, que es uno de los objetivos del arte. La cuestión de la importancia moral del arte y su función social es otra de las preocupaciones que el autor aborda en la obra. El artista crea, encarna o rechaza valores en las obras de arte, sin una pretensión de objetividad. También carece de esta objetividad la crítica del arte, que cae en las modas, los prejuicios y el esnobismo (Fernie, 2013; Preziosi, 2009).

Así mismo, en Meditaciones sobre un caballo de juguete y otros ensayos sobre la teoría del arte traza un paralelismo entre la función que cumple el arte en el ser humano con la utilidad 
de un caballo de madera en un niño. Insistiendo en la idea de que el arte no busca la imitación, sino la representación, señala la importancia de la función y el uso de la obra de arte por encima de su logro estético (Gombrich, 1963/1998). También es destacable el ensayo El sentido del orden. Estudio sobre la psicología de las artes decorativas (Gombrich, 1979/2010) donde el autor centra el tema en la configuración psicológica y el valor de las artes suntuarias. Para el autor, subyace en ellas un sentido profundo del orden dentro de su abstracción, una tendencia repetitiva que evita la monotonía y la uniformidad, guardando una estrecha relación con la expresión musical, donde está presente este mismo ritmo.

Por su parte, en el libro La imagen y el ojo: nuevos estudios sobre la psicología de la representación pictórica el autor recopila los textos de unas conferencias de años anteriores donde propone una explicación de la idea de la perspectiva, como elemento condicionado por la vista y sus percepciones (Gombrich, 1960/1987). La perspectiva no representa el mundo tal cual lo vemos, sino de la forma que tiene la vista humana de percibir la realidad, idea que recoge de los estudios de Erwin Panofsky (1927/1985). Para ello, el autor compara posturas desde la psicología, la filosofía del arte y la comunicación, permitiéndole trazar un completo panorama de cómo se entiende la imagen a lo largo de la historia de la humanidad, con especial énfasis en la importancia del espectador. Precisamente el valor de la percepción del espectador es uno de los ideales que recorren toda la obra de Gombrich. Para el autor, una vez que el artista crea una obra, esta solo vive a través del público que la observa, convirtiéndose este en un factor clave a tener en cuenta en la interpretación artística. A su vez, la visión del espectador no está libre de sus planteamientos personales, su tradición cultural y su concepción social.

\section{Últimas perspectivas}

En las últimas décadas han aparecido algunos planteamientos muy interesantes, como el trabajo de Nelson Goodman y sobre todo de Howard Gardner, al desarrollar el Proyecto Zero en la Universidad de Harvard para la comprensión de la naturaleza del pensamiento artístico y su estímulo educativo (Goodman, 1968/1976; Gardner, 1982/1997). Este último, ha desarrollado interesantes teorías en torno al concepto de la creatividad, en relación con la inteligencia, además de plantearse la concepción artística de los niños. Dentro del análisis del arte infantil, se han identificado diferentes fases que vinculan ciertos estilos de expresión plástica con las etapas de desarrollo de los menores. La formación artística para los pequeños también ayuda a facilitar su proceso de maduración personal, estimulando áreas como la creatividad, el pensamiento flexible, la toma de decisiones, la fluidez comunicativa o la resolución de problemas.

En esta misma línea y en relación con la pérdida del sentido elitista que ha experimentado el arte en la última mitad del pasado siglo tuvo su origen la aparición de la terapia artística, concibiendo el proceso creativo que cristaliza en la obra de arte como una vía para el desarrollo de emociones positivas -ya sea en las artes plásticas, musicales o escénicas-. Sin constituir programas terapéuticos reglados, existen casos históricos como el de la artista Frida Kalho, que utilizaba la expresión artística como medio para combatir el dolor causado por sus enfermedades, o el de la artista judía Helga Weissová -superviviente del exterminio nazi-, que pintaba escenas relacionadas con el holocausto para tratar de superar las secuelas de la tortura.

Otro ámbito interesante tiene que ver con la idea de que la capacidad de producir objetos artísticos está limitada al ser humano, al entenderse que el hombre es el único animal racional capaz de expresar sentimientos y emociones utilizando el arte. Los experimentos que se han hecho para romper esta concepción provocaron muchas dudas en el ámbito académico, al exponer las pinturas resultantes de hacer que animales -como monos o elefantes- tracen manchas en un lienzo, sin decir su procedencia real. Cuando la crítica interpretó estos cuadros como si fuesen 
obras humanas, detectando rasgos asociados a la influencia de movimientos pictóricos, provocaron debates sobre los límites de lo artístico, que son bastante difusos.

También desde el campo de la neurociencia, las investigaciones que estudian el funcionamiento del cerebro han sido capaces de propiciar resultados interesantes al analizar qué papel desempeña cada uno de los hemisferios cerebrales. Mientras que el izquierdo se encarga de las funciones del lenguaje, la lógica, los números, el análisis o el orden, el derecho se ocupa de la creatividad, los sueños, las ideas, los símbolos y las imágenes. Los procesos artísticos propician un desarrollo conjunto de ambos hemisferios, al entender la obra de arte como un proceso comunicativo y creativo a partes iguales. Dentro de la neuropsicología también se ha podido trabajar casos de artistas con enfermedades mentales. Por ejemplo, Roger Vigouroux menciona al pintor Vincent van Gogh, que probablemente padeciese epilepsia, como modelo de genio atormentado en vida. Su consciencia de que pintando hacía frente a la enfermedad, se relaciona con la idea del arte como terapia, expuesta anteriormente (Vigouroux, 1992/1995). Por otra parte, la premisa de si la creatividad, el genio artístico y la patología tienen un componente genético vinculante sigue todavía abierta.

Todos estos acercamientos que se han analizado y otros que, seguro, están por venir, permitirán tener una visión más certera de cómo funciona la mente humana en relación a las obras de arte, así como los mecanismos de creación y percepción. Desde el enfoque de la disciplina, debemos también mencionar las aproximaciones de la profesora Gisèle Marty que resaltan el valor de la Psicología del Arte en los últimos años, a la vez que señala la importancia de estudiar las emociones y los procesos artísticos (Marty, 1997, 1999, 2000). La Psicología del Arte, pese a la pluralidad de disciplinas que implica, todavía comienza a iniciar su despegue como campo independiente que suscita un amplio interés.

\section{Referencias}

Álvarez Villar, A. (1974). Psicología del arte. Madrid, España: Biblioteca Nueva.

Arnheim, R. (1986). El pensamiento visual. Barcelona, España: Paidos (1. ${ }^{a}$ Ed. 1969).

Arnheim, R. (1989). Nuevos ensayos sobre Psicología del Arte. Madrid: Alianza (1. ${ }^{a}$ Ed. 1986).

Arnheim, R. (1995). Hacia una psicología del arte: Arte y entropía. Ensayo sobre el desorden y el orden. Madrid, España: Alianza (1. ${ }^{a}$ Ed. 1966).

Arnheim, R. (2005). Arte y percepción visual: psicología del ojo creador. Madrid, España: Alianza (1. ${ }^{\mathrm{a}}$ Ed. 1954).

Bal, M. (1991). Reading «Rembrandt»: Beyond the Word-Image Opposition. Cambridge, UK: Cambridge University Press.

Billgren, E. (2011). What is Art and 100 other very important questions. Lugar de edición: Bokförlaget Langenskiöld.

D'Alleva, A. (2005). Methods \& Theories of Art History. Londres, UK: Laurence King.

Domínguez Perela, E. (1993). Conducta estética y sistema cultural: introducción a la psicología del arte. Madrid, España: Editorial Complutense.

Eco, U. (1970). La definición del Arte. Barcelona, España: Martínez Roca (1. ${ }^{a}$ ed. 1968).

Fernie, E. (2013). Art History an its Methods. A Critical Anthology. Londres, UK: Phaidon.

Foster, H. (1996). The Return of the Real. The AvantGarde at the End of the Century. Cambridge, UK: MIT Press.

Francés, R. (1985). Psicología del arte y de la estética. Madrid, España: Akal (1. ${ }^{a}$ Ed. 1979).

Freud, S. (2001). Leonardo da Vinci. Barcelona, España: Belacqua (1. ${ }^{\text {a }}$ Ed. 1910).

Freud, S. (2011). El Moisés de Miguel Ángel. Madrid, España: Casimiro (1. ${ }^{a}$ Ed. 1914).

Gardner, H. (1997). Arte, mente y cerebro. Barcelona, España: Paidós (1. ${ }^{a}$ Ed. 1982).

Gardner, H. (1997). Educación artística y desarrollo humano. Barcelona, España: Paidós (1. ${ }^{a}$ Ed. 1994).

Gombrich, E. H. (1971). Freud y la psicología del 
Arte: Estilo, forma y estructura a la luz del psicoanálisis. Barcelona, España: Barral.

Gombrich, E. H. (1987). La imagen y el ojo: nuevos estudios sobre la psicología de la representación pictórica. Madrid, España: Alianza (1. ${ }^{a}$ Ed. 1960).

Gombrich, E. H. (1998). Meditaciones sobre un caballo de juguete y otros ensayos sobre la teoría del arte. Madrid, España: Debate (1. ${ }^{a}$ Ed. 1963).

Gombrich, E. H. (2008). Arte e ilusión. Estudio sobre la psicología de la representación pictórica. Londres, UK: Phaidon (1. ${ }^{a}$ Ed. 1956).

Gombrich, E. H. (2010). El sentido del orden: estudio sobre la psicología de las artes decorativas. Londres, UK: Phaidon (1. ${ }^{a}$ Ed. 1979).

Goodman, N. (1976). Los lenguajes del arte. Los sistemas simbólicos del arte. Barcelona, España: Seix Barral (1. ${ }^{a}$ Ed. 1968).

Harrison, C. y Wood, P. (2003). Art in Theory. 19002000. An Antology of Changing Ideas. Oxford: Blackwell Publishers.

Harrison, C.; Wood, P. y Gaiger, J. (1998). Art in Theory. 1815-1900. An Antology of Changing Ideas. Oxford: Blackwell Publishers.

Hatt, M. y Klonk, C. (2006). Art History. A critical introduction to its methods. Manchester; UK: Manchester University Press.

Hogg, J. (1975). Psicología y artes visuales. Barcelona, España: Gustavo Gili (1. ${ }^{a}$ Ed. 1969).

Jung, C. G. (2009). El hombre y sus símbolos. Barcelona, España: Paidos. (1. ${ }^{a}$ Ed. 1964).

Kozulin, A. (1994). La Psicología de Vygotski: biografía de unas ideas. Madrid, España: Alianza (1. a ed. 1990 en inglés).

Krauss, R. (1993). The Optical Unconscious. Cambridge, UK: MIT Press.

Kris, E. (1952). Psychoanalytic Explorations in Art. New York: International Universities Press.

Marty, G. (1997). «Hacia la Psicología del Arte», Psicothema, 9(1), 57-68.

Marty, G. (1999). Psicología del arte. Madrid, España: Pirámide.
Marty, G. (2000). Los problemas de una Psicología del Arte. Arte, Individuo y Sociedad, 12, 61-70.

Mirzoeff, N. (2003). Una introducción a la cultura visual. Barcelona, España: Paidós. (1. ${ }^{a}$ Ed. 1999).

Monserrat, J. (1998). La percepción visual. La arquitectura del psiquismo desde el enfoque de la percepción visual. Madrid, España: Biblioteca Nueva.

Mulvey, L. (1975). Visual Pleasure and Narrative Cinema. Screen, 16(3), 6-18.

Panofsky, E. (1985). La perspectiva como forma simbólica. Barcelona, España: Tusquets. (1. ${ }^{a}$ Ed. 1927).

Pollock, G. (1988). Vision and Difference: Femininity, Feminism, and Histories of Art, Londres, UK: Routledge.

Preziosi, D. (2009). The Art of Art History: A Critical Antthology. New York: Oxford University Press.

Schneider Adams, L. (1996). Arte y psicoanálisis. Madrid, España: Cátedra (1. ${ }^{a}$ Ed. 1993).

Schuster, M. y Beisl, H. (1982). Psicología del arte: cómo influyen las obras de arte. Barcelona, España: Blume (1. ${ }^{a}$ Ed. 1978).

Verstegen, I. (2005). Arnheim, Gestalt and Art. A Psychological Theory. Wien: Springer.

Vigouroux, R. (1995). La fábrica de lo bello. Barcelona, España: Prensa Ibérica (1. ${ }^{a}$ Ed. 1992).

Vygotsky, L. S. (2003). La imaginación y el arte en la infancia. Madrid, España: Akal (1. ${ }^{a}$ Ed. 1930).

Vygotsky, L. S. (2006). Psicología del arte. Barcelona, España: Paidós (1. ${ }^{a}$ Ed. 1968).

Weber, J. P. (1966). La psicología del arte. Buenos Aires, Argentina: Paidós (1. ${ }^{\mathrm{a}}$ Ed. 1958).

Wollheim, R. A. (1984). Painting as an Art. Washington: Harvard University Press.

Worringer, W. (1959). El arte y sus interrogantes. Buenos Aires, Argentina: Nueva Visión (1. ${ }^{a}$ Ed. 1956).

Worringer, W. (2008). Abstracción y naturaleza. Una contribución a la psicología del estilo. México: Fondo de Cultura Económica (1. ${ }^{\mathrm{a}}$ Ed. 1908). 